\title{
A participação escolar de alunos com deficiência na percepção de seus PROFESSORES ${ }^{1}$
}

\author{
SCHOOL participation of Students With disabilities from the perception of their \\ TEACHERS
}

\author{
Patricia Bettiol $\mathrm{ABE}^{2}$ \\ Rita de Cássia Tibério ARAÚJO3
}

RESUM O : a identificação do nível de participação escolar do aluno com deficiência é fundamental para o
monitoramento do processo educacional inclusivo. Requer o uso deinstrumentos demedida que contemplem
a funcionalidadeperantedemandas escolares específicas eque possam, ao mesmo tempo, motivar o professor
a uma reflexão sobreo seu julgamento acerca do desempenho dessealuno. A School Function A ssessment (SFA)
éuminstrumento quefavorecea identificação denecessidades especiais do aluno com deficiência sob parâmetros
de funcionalidade e participação. N essa perspectiva, este estudo teve como objetivo analisar a influência da
aplicação da SFA no julgamento do professor sobre a participação escolar do seu aluno com deficiência.
Participaram do estudo oito professores que responderam sobre a participação escolar de seus nove alunos,
por meio da SFA e de roteiro de entrevista. Os resultados demonstraram que, para cinco professores, a SFA
favoreceu a percepção da participação com foco na demanda deatividadesepropiciou reflexões queabrangeram
os seguintes destaques: necessidade de avaliação da participação fora da sala de aula, relação entreo grau de
deficiência ea participação, entendimento deespecificidades do desempenho, importância do recurso adaptado
paraneutralizar a incapacidadeeimportância do desvio do foco deatenção da deficiência para a funcionalidade.

PALAV RAS-CHAVE: educação especial; educação inclusiva; terapia ocupacional; partici pação do aluno.

ABSTRACT: Theidentification of thelevel of school participation of disabled students is crucial for monitoring theinclusiveeducational process. It requires theuse of measuring instruments that providefunctionality before school specific demands, and that at the same time can motivate the teacher to reflect on his judgment about the performance of students with disabilities. School Function Assessment (SFA) is a tool that hel ps recognize the special needs of students with disabilities according to parameters of functionality and participation. Thus, this study analyzed the influence of the use of SFA on the teacher's judgment of student participation and performance. Eight teachers responded regarding the participation of ninestudents with disabilities through the use of the SFA and a questionnaire. The results indicated that, for five teachers, SFA helped with the perception of thestudent's participation, focusing on theactivity demand and brought reflections on: the need of evaluation not just in theclassroom, co-relation between the degree of disability and the participation of the

\footnotetext{
${ }^{1}$ Trabalho baseado na dissertação: Desempenho funcional nas atividades de rotina escolar de alunos com Necessidades Educacionais Especiais na perspectiva do professor. A poio financeiro: CAPES.

${ }^{2}$ Terapeuta Ocupacional. M estre em Educação pelo Programa de Pós-Graduação em Educação pela Unesp Campus de Marília. patricia.abe@gmail.com

${ }^{3}$ Terapeuta Ocupacional. Doutora em Educação. Docentedo Departamento deEducação Especial edo Programa dePós-Graduação em Educação da Unesp - Campus deM arília. ritac@marilia.unesp.br
} 
student, understanding of the specificities of the performance, importance of the adaptation to neutralize incapacity and the importance of the focus deviation from the disability toward functionality.

KEYWO RK S: Special Education; School Inclusion; Occupational Therapy; Student Participation.

\section{InTRODUÇão}

A experiência escolar do aluno com deficiência é um tema de abordagem complexa devido aos múltiplos fatores que a influenciam, sendo foco deste estudo a sua discussão com base no conceito de funcionalidade e, consequentemente, na relação entre a capacidade funcional da pessoa ea demanda ambiental.

A participação escolar do aluno com deficiência depende da sua capacidadefuncional perantedemandas ambientais específicas. Isso significa que as suas necessidades educacionais especiais (NEE) devem ser identificadas na sua interação com o meio (DELMASSO; ARAÚJO, 2008). Portanto, a restrição da participação do indivíduo em determinado contexto resulta de condições ambientais desfavoráveis ao desempenho. (OMS, 2003)

Esse entendimento é central na perspectiva inclusiva, porquanto a expressão NEE refira-se também a diferenças de desempenho relacionadas com deficiências ou dificuldades escolares, exigindo diferentes formas de interação pedagógica e/ ou suportes adicionais, tais como recursos, metodologias ecurrículos adaptados duranteo seu percurso escolar (GLAT; BLAN CO, 2007).

Para que se possa agir favoravelmente à qualidade da experiência escolar do aluno com deficiência é preciso levar em conta a discrepância entre a capacidade funcional do indivíduo e as demandas funcionais das atividades que fazem partedo contexto de ação, bem como determinar pontos que possam impedir sua partici pação. Sob este prisma, a inclusão escol ar requer mudança e esforço de planejamento nas diversas escal as da problemática inclusiva, abrangendo políticas educacionais, questões do cotidiano da escola, atividades na sala de aula, desempenho do al uno e rede de apoio à escola (OLIVEIRA; LEITE, 2007) .

No que concerne à aval iação dos resultados da experiência do aluno com deficiência em classe regular, há necessidade deestudos queaval iem eanalisem a sua partici pação nos diferentes cenários enas variadas atividades que compõem a rotina escolar (ARAÚJO, 1998; DE CARLO, 2006; OM OTE, 2004).

Os alunos com NEE apresentam dificuldades em responder positivamenteàs demandas das tarefas escolares, ea aval iação da sua partici pação é imprescindível, uma vez que poderá auxiliar na definição de estratégias facilitadoras da experiência. 
Na identificação de NEE, devem ser levados em conta os aspectos da funcionalidade, definida como o uso das capacidades para um fim, e os da incapacidade, entendida como a lacuna que se estabelece entre as capacidades do indivíduo eas demandas ocupacionais (ARAÚJO, 1998; OM OTE, 2004; OMS, 2003; VERBRUGGE; JETTE, 1994). O conhecimento da funcional idade eda incapacidade do aluno orienta a seleção de estratégias facilitadoras da participação, tendo-se como foco de intervenção não apenas o aluno com deficiência, mas também o ambiente da experiência (MUN GUBA, 2007).

Segundo Ainscow (2009), a inclusão escolar pressupõe um processo em três níveis assim denominados: a) "estar na escola", na medida em que os alunos deficientes devem estar no mesmo espaço geográfico que os demais alunos, transpondo as barreiras das antigas classes especiais; b) "participação", quesignifica dar condições para que os al unos, além de secolocarem presentes no mesmo espaço, participem das atividades, c) "aquisição de conhecimentos", quesintetiza a razão da existência da instituição escolar.

O Ministério da Educação e Cultura (BRASIL, 2006) esclarece que inclusão implica em possibilidade deinteração, acol hida, socialização, adaptação do indivíduo ao grupo e, sobretudo, da modificação da escola para atendêlo.

Portanto, a inclusão do al uno com deficiência nas salas deensino regular requer dois movimentos, o do aluno, que deve se esforçar e se capacitar para responder positivamenteàs demandas do processo deescolarização, eo movimento da escola que deve se organizar para recebê-lo. Da união dos esforços do al uno e da escola espera-seum bom resultado, no âmbi to da aquisição deconhecimentose no da partici pação na rotina escolar.

Com relação aos recursos utilizados na avaliação da participação do al uno na escola, a School Function A ssessment (SFA ) éum instrumento de avaliação do desempenho funcional que identifica as NEE frente às demandas de rotina escolar. Esse instrumento de medida padronizado, utilizado na prática clínica e em pesquisas na área de educação especial por terapeutas ocupacionais, avalia a participação escolar do aluno com deficiência por meio de observação direta ou através de entrevistas com pessoas que conheçam a sua rotina (MANCINI et al., 2000; MAN CINI; COSTER, 2004; SCHENKER; COSTER; PARUSH, 2005).

Neste estudo consi derou-se a importância da aplicação daSFA coma partici pação do professor, para informar sobreo aluno eopinar sobreo instrumento, visto que, esse instrumento possi bilita a identificação de NEE não por categorias de deficiências, mas, sim, por demandas funcionais das atividades escolares. N essa perspectiva, o objetivo desta pesquisa foi analisar a influência da aplicação daSFA no julgamento do professor sobre a participação escolar do seu aluno com deficiência. 


\section{Método}

\subsection{Participantes}

Participaram desta pesquisa oito professores de classes regulares do ensino fundamental que responderam sobre a participação escolar de seus respectivos al unos com NEE.

Os professores foram, em sua maioria, do gênero feminino (7). Compuseram a amostra dois professores com formação no Magistério e seis graduados em Pedagogia. Um dos professores, com formação no magistério, cursava o segundo ano do curso depedagogia. Dos seis pedagogos, cinco possuíam Habilitação em Administração Escolar eum professor havia cursado a H abilitação em Educação Especial nas Ár reas de Deficiência Auditiva e Deficiência Mental. Preval eceu a proporção de um aluno por professor, encontrando-se apenas um professor com dois alunos em uma mesma sala deaula. Quanto ao ensino dealunos com NEE, do total de oito professores, cinco mencionaram experiência pedagógica prévia com essa população em classe regular (Quadrol).

\begin{tabular}{|cc|c|l|l|}
\hline $\begin{array}{c}\text { Professor } \\
\text { (aluno) }\end{array}$ & Gênero & Série & \multicolumn{1}{|c|}{ Formação/ Especialização } & \multicolumn{1}{c|}{$\begin{array}{c}\text { Tempo de experiência no ensino de alunos } \\
\text { com NEE }\end{array}$} \\
\hline $\begin{array}{c}\text { P1 } \\
\text { (A1) }\end{array}$ & Fem & 4 & $\begin{array}{l}\text { Magistério } \\
\text { Cursando 2 ano em Pedagogia }\end{array}$ & Sem experiência anterior \\
\hline $\begin{array}{c}\text { P2 } \\
\text { (A2) }\end{array}$ & Fem & 2 & $\begin{array}{l}\text { Pedagogia há 4 anos / } \\
\text { não relatou especialização }\end{array}$ & Alunos em sala regular (não relatou o tempo) \\
\hline $\begin{array}{c}\text { P3 } \\
\text { (A3) }\end{array}$ & masc & 2 & $\begin{array}{l}\text { Magistério / } \\
\text { não relatou especialização }\end{array}$ & Sem experiência anterior \\
\hline $\begin{array}{c}\text { P4 } \\
\text { (A4 A5) }\end{array}$ & Fem & 3 & $\begin{array}{l}\text { Supervisão Escolar, Administração } \\
\text { Escolar e em Educação Especial em DA, } \\
\text { DM. }\end{array}$ & $\begin{array}{l}\text { Alunos em sala regular (não relatou o tempo) } \\
\text { e Escola Especial (5anos) }\end{array}$ \\
\hline $\begin{array}{c}\text { P5 } \\
\text { (A6) }\end{array}$ & Fem & 4 & $\begin{array}{l}\text { Pedagogia há 3 anos / } \\
\text { Habilitação em Administração }\end{array}$ & Alunos em sala regular (9anos) \\
\hline $\begin{array}{c}\text { P6 } \\
\text { (A7) }\end{array}$ & Fem & 3 & $\begin{array}{l}\text { Pedagogia há 10 anos / } \\
\text { Habilitação em Administração e } \\
\text { Educação Infantil; } \\
\text { Especialização em Psicopedagogia, } \\
\text { Pedagogia há 4 anos / } \\
\text { Habilitação em Administração }\end{array}$ & Alunos em sala regular (2anos) \\
$\begin{array}{c}\text { P7 } \\
\text { (A8) }\end{array}$ & Fem & 2 & $\begin{array}{l}\text { Pedagogia há 2 anos / } \\
\text { Habilitação em Administração }\end{array}$ \\
\hline $\begin{array}{l}\text { P8 } \\
\text { (A9) }\end{array}$ & Fem & Alunos em sala regular (3anos) \\
\hline
\end{tabular}

Quadro 1 - Caracterização dos professores.

Os novealunos sobre os quais incidiu o foco da presente investigação apresentavam idademédia de 9,5 anos $(D P=1,25)$. Compuseram a amostra quatro alunos do gênero feminino e cinco alunos do gênero masculino, sendo três da segunda série, três da terceira série e três da quarta série. Quanto às condições de deficiência, houve um al uno com deficiência auditiva severa, um com deficiência visual classificada como baixa visão, um com Síndrome de Asperger e seis com deficiência física. Estes últimos com deficiência física, categorizados, segundo 
cadastro da Secretaria M unicipal deEducação, da seguinteforma: três com paral isia cerebral e três com deficiência "física/ outros". Na categoria deficiência "física/ outros" foi identificada uma segunda classificação: dois al unos com malformação congênita de membros superiores eum com tremor não especificado em membros superiores (Quadro 2).

\begin{tabular}{|c|c|c|cc|l|}
\hline Aluno & Gênero & $\begin{array}{c}\text { Data } \\
\text { Nascimento }\end{array}$ & $\begin{array}{c}\text { Idade } \\
\text { em anos } \\
\text { (Julho/08) }\end{array}$ & $\begin{array}{c}\text { Série } \\
\text { Escolar }\end{array}$ & \multicolumn{1}{|c|}{ Deficiência } \\
\hline A1 & fem. & $9 / 7 / 1997$ & 11 & 4 & DA - severa \\
\hline A2 & masc. & $24 / 4 / 2000$ & 8,2 & 2 & DV - baixa visão \\
\hline A3 & fem. & $19 / 3 / 2000$ & 8,3 & 2 & DF - malformação congênita MS/D \\
\hline A4 & masc. & $15 / 7 / 1999$ & 9 & 3 & Autismo - Síndrome Asperger \\
\hline A5 & masc. & $8 / 1 / 1999$ & 9,5 & 3 & $\begin{array}{l}\text { DF - malformação congênita } \\
\text { MMSS }\end{array}$ \\
\hline A6 & masc. & $27 / 3 / 1997$ & 11,3 & 4 & DF - tremor MMSS \\
\hline A7 & masc. & $22 / 3 / 1998$ & 10,3 & 3 & DF - PC/ MS D e MI D \\
\hline A8 & fem. & $20 / 8 / 2000$ & 7,9 & 2 & DF - PC / MMII e MMSS \\
\hline A9 & fem. & $\begin{array}{c}19 / 4 / 1998 \\
\text { masc. - masculino }\end{array}$ & 10,2 & $\begin{array}{c}4 \\
\text { A - Alunos }\end{array}$ & DF - PC / MS D e MI D \\
\hline fem. - feminino & \multicolumn{5}{|l|}{ DM - Deficiencia Mental } \\
\hline DF - Deficiencia Física \\
\hline DV - Deficiência Visual
\end{tabular}

Quadro 2- Caracterização dos alunos participantes, segundo o cadastro de Alunos com $\mathrm{N}$ ecessidades Educacionais Especiais da Secretaria Municipal de Educação.

\subsection{ONSIDERAÇões Éticas}

O trabalho foi encaminhado ao Comitê de Ética em Pesquisa da Faculdade de Filosofia e Ciências, Unesp - Marília, e aprovado sob o parecer $n^{\circ}$. 2238/ 2008. Os professores e responsáveis pelos alunos assinaram o Termo de Consentimento Livree Esclarecido para a participação voluntária na pesquisa.

\subsection{I nstrumentos e Procedimentos de coleta de dados}

A col eta de dados teve início com o levantamento de al unos com NEE matriculados em classes regulares do Ciclo I do Ensino Fundamental da Rede Municipal deEnsino, em uma cidadedo interior paulista. Utilizou-sea terminologia NEE devido ao seu uso nos cadastros de classificação da Secretaria M unicipal de Educação.

Deposse desselevantamento, selecionou-sea escola com maior número dealunos com deficiência matriculados em classes regulares equetambém oferecia variados tipos de acometimento. Considerou-sequea disponibilidade dessa escola para receber al unos com deficiência favorecia a exequibilidadedo estudo sob aspectos 
de predisposição dos professores para a participação, sendo esta uma condição importantediante da natureza exploratória da presenteinvestigação. Encontrou-se nessa situação a matrícula deseis al unos, eapenas um del es com paral isia cerebral . Tendo-se constatado o grau leve decomprometimento motor do aluno com paral isia cerebral da escola sel ecionada e levando em conta a abrangência das necessidades especiais que podem advir da paralisia cerebral, optou-se por incluir na amostra todos os alunos com paralisia cerebral matriculados no Ciclo I do Ensino Fundamental, da Rede Municipal estudada, no período de realização da pesquisa. Dessa forma, os três al unos com paralisia cerebral representaram a totalidadedesse diagnóstico na amostra desteestudo.

Para a coleta de dados foram utilizados dois instrumentos, sendo eles: (a) School Function A ssessment (SFA ), para avaliar o desempenho do aluno em tarefas da rotina escolar que dão suporteà sua participação nas atividades pedagógicas; (b) um roteiro de entrevista, elaborado pelas pesquisadoras, para avaliar a importância queo professor atribui ao uso daSFA , permitindo também identificar a importância da SFA para direcionar a percepção do professor com foco no desempenho do al uno perante as demandas de atividades.

Com relação àSFA, esteinstrumento oferece a possibilidadedeestudar a participação escolar do aluno com deficiência em ambiente de classeregular ou ambiente de classe especial, entendendo por atividade as ações específicas necessárias para a execução de uma tarefa. É composto por três partes, a primeira que avalia o nível de participação do aluno em ambientes ou situações escolares previamente estabelecidos pel o instrumento. A segunda parteo suporte oferecido por meio deassistência deterceiros ou deadaptações para queo al uno queavalia com deficiência realize as tarefas. A terceira parte que avalia as atividades específicas necessárias para a realização das tarefas nos ambientes destacados pelo instrumento.

Neste estudo, foi utilizada a primeira parte da SFA, que avalia a participação do aluno em seis ambientes ou situações escolares: sala de aula (ambientedeclasse regular), transporte, transição (deslocamento entre os diversos ambientes no interior da escola), pátio, banheiro, lanche. O nível de participação em cada um desses contextos é aval iado segundo uma escala com variação de la 6 pontos, podendo-seobter um escore bruto total de 36 pontos. A pontuação para cada item dos ambientes escol ares segue a seguinte classificação: 1 - participação extremamente limitada, 2 - partici pação em al gumas atividades, 3 - partici pação em todos os aspectos com supervisão constante, 4 - participação em todos os aspectos com assistência ocasional, 5 - participação total modificada, e 6 partici pação total (COSTER; MAN CINI; LUDLOW, 1999).

Utilizou-se somente a primeira parte da SFA tendo em vista que esta pesquisa dirigiu a atenção para a percepção do professor acerca da participação escolar do seu al uno com deficiência, não estando em destaque neste artigo nem a questão do auxílio proporcionado ao aluno nem o detal hamento das tarefas realizadas. 
O roteiro deentrevista foi composto por cinco questões com as seguintes indagações ao professor: a primeira sobre o seu conhecimento acerca da SFA; a segunda sobre a sua percepção de desempenho do aluno com deficiência em comparação com os demais alunos da classe; a terceira queverificou se o professor percebia a sua mudança no julgamento do desempenho do seu aluno após ter respondido ás perguntas da primeira parte da SFA; a quarta que foi um desdobramento da terceira pergunta condicionado à confirmação de mudança de percepção do professor quanto ao desempenho do al uno; a quinta que abordou a opinião do professor acerca da contribuição daSFA para a sua atuação em sala de aula.

Os dois instrumentos foram aplicados individualmente. Adotou-se como parâmetro para a pontuação daSFA o nível esperado de participação para a etapa escolar, isto é, os professores foram alertados de quea sua avaliação sobreo desempenho do aluno deveria ser feita com basena partici pação esperada para a série escolar.

A coleta de dados iniciou-se com a aplicação de duas perguntas do rotei ro de entrevista, as quais indagavam sobre o conhecimento daSFA esobreo desempenho geral dos alunos, prosseguindo com a aplicação de toda a primeira parte daSFA , e finalizando com a aplicação das três questões que versavam sobre a percepção do professor acerca das contribuições da SFA na avaliação do desempenho escolar do aluno.

\subsection{Procedimentos para análise dos dados}

A análise dos dados coletados teve como ponto de partida a descrição da participação escolar de cada aluno, segundo os critérios declassificação daSFA .

Essa análise permitiu a identificação do índice de disfunção de participação em medida percentual, tendo-se como parâmetro de comparação o nível de desempenho esperado para a série escolar.

A análise dos dados de entrevista ocorreu com base nos tópicos das perguntas (ANDRÉ, 1983) que precederam e sucederam à aplicação da SFA, permitindo a identifi cação de conteúdos indicativos de mudança da percepção do professor com relação à partici pação escolar deseu al uno.

\section{RESUltados E discussão}

Os resultados da análise dos dados referentes à aplicação da Partel da SFA sobrea partici pação dos alunos nos ambientes escolares, segundo a opinião dos professores, demonstraram que quatro al unos obtiveram o escore máximo de 36 pontos, havendo variação de pontuação para os demais alunos (Tabela 1). 
Tabela 1 - Escores brutos de participação dos alunos nos ambientes escolares SFA Partel.

\begin{tabular}{cccccccc}
\hline \multicolumn{7}{c}{ PARTICIPAÇ̃̃O NOS AMBIENTES } \\
\hline Aluno & $\begin{array}{c}\text { Participação } \\
\text { geral em classe } \\
\text { regular }\end{array}$ & $\begin{array}{c}\text { Patio } \\
\text { recreio / } \\
\text { intervalo }\end{array}$ & Transporte & $\begin{array}{c}\text { Banheiro/ } \\
\text { higiene }\end{array}$ & Transição & Lanche & TOTAL \\
\hline A1 & 6 & 6 & 6 & 6 & 6 & 6 & $\mathbf{3 6}$ \\
A2 & 6 & 6 & 6 & 6 & 6 & 6 & $\mathbf{3 6}$ \\
A3 & 6 & 6 & 6 & 6 & 6 & 6 & $\mathbf{3 6}$ \\
A4 & 6 & 6 & 5 & 6 & 3 & 4 & $\mathbf{3 0}$ \\
A5 & 6 & 6 & 6 & 6 & 6 & 6 & $\mathbf{3 6}$ \\
A6 & 5 & 6 & 6 & 6 & 5 & 6 & $\mathbf{3 4}$ \\
A7 & 4 & 5 & 5 & 1 & 6 & 4 & $\mathbf{2 5}$ \\
A8 & 6 & 5 & 6 & 6 & 6 & 6 & $\mathbf{3 5}$ \\
A9 & 3 & 4 & 6 & 6 & 6 & 6 & $\mathbf{3 1}$ \\
\hline
\end{tabular}

Os alunos com distúrbios neuromusculares e síndrome de Asperger não atingiram o nível máximo de partici pação queéesperado para a sérieescolar, podendo-se consi derar que as condições deacessi bilidade da escola, mediante as necessidades demobil idade, coordenação motora e de comportamento constituem fatores potencial menterestritivos da participação.

Identifica-se ainda a participação expressiva de seis alunos em todos os ambientes e atividades de rotina escolar. Exceção ocorreu em três situações: a participação reduzida do aluno A7, sobretudo no ambiente do banheiro onde apresenta participação extremamente limitada; a participação reduzi da do al uno A9 no ambiente de classe regular onde necessita de supervisão constante e a participação reduzida do al uno A 4 no ambiente de transição, necessitando também de constante supervisão. N os demais ambientes foram encontrados os seguintes níveis de partici pação: total, total modificada ecom assistência ocasional .

Na análise do índice de redução da partici pação escolar (Tabela 2), os resultados demonstram que, na pontuação geral, quatro al unos atingiram $100 \%$ do desempenho esperado para qual quer al uno da classe, dois al unos obtiveram índices percentuais mínimos de disfunção e três alunos apresentaram índice de disfunção acima de $10 \%$. O maior índice de disfunção obtido pelo aluno (A7) relacionou-seà menor pontuação de participação no ambientedo banhei ro (Tabela 1), eeste resultad o sinal iza que o risco de restrição de participação escolar do aluno com deficiência extrapola as questões pedagógicas de ensino em classeregular ou especial. Portanto, os resultados deste estudo ampliam os argumentos em favor 
da necessidade deajustes na organização institucional enos domínios das barreiras arquitetôni cas para atender às demandas funcionais diferenciadas dos alunos com deficiência, conformerecomendam Manzini eCorrêa (2008), Oliveira eLeite(2007), Fernandes, A ntunes eGlat (2007).

Tabela 2 - Índice de participação do aluno.

\begin{tabular}{cccc}
\hline Aluno & $\begin{array}{c}\text { Pontuação total na } \\
\text { SFA }\end{array}$ & $\begin{array}{c}\text { Nível de } \\
\text { desempenho (\%) }\end{array}$ & Disfunção (\%) \\
\hline A1 & 36 & 100 & 0 \\
A2 & 36 & 100 & 0 \\
A3 & 36 & 100 & 0 \\
A4 & 30 & 83,3 & 16,7 \\
A5 & 36 & 100 & 0 \\
A6 & 34 & 94,4 & 5,6 \\
A7 & 25 & 69,4 & 30,6 \\
A8 & 35 & 97,2 & 2,8 \\
A9 & 31 & 86,1 & 13,9 \\
\hline
\end{tabular}

$\mathrm{Na}$ análise das respostas dos professores ao roteiro de entrevista (Quadro 3), verificou-se que a maioria dos professores não conhecia a SFA , com exceção de um professor (P7) que alegou ter "ouvido falar", mas não soube determinar como tomou conhecimento.

Com relação ao desempenho acadêmico, o questionário solicitava que o desempenho dos al unos fosse avaliado em um intervalo de 0 a 10, sendo 0 para o pior desempenho e 10 para o mel hor desempenho possível. Três professores não pontuaram o desempenho dos al unos, no entanto, responderam queo desempenho do seu al uno com deficiência correspondia ao dos outros al unos da classe. 


\begin{tabular}{|c|c|c|c|c|c|c|}
\hline 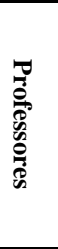 & $\underset{\Xi}{E}$ & $\begin{array}{c}1 \text { - Você } \\
\text { conhece a } \\
\text { avaliação } S F A \\
\text { (Avaliação da } \\
\text { função } \\
\text { escolar)? }\end{array}$ & $\begin{array}{c}2 \text { - Como você } \\
\text { classificaria o } \\
\text { desempenho do aluno } \\
\text { em comparação com } \\
\text { os outros alunos da } \\
\text { classe (pontue de } 0 \text { - } \\
10) ?\end{array}$ & $\begin{array}{c}\text { 3 - Após } \\
\text { responder ao } \\
\text { questionário } \\
(S F A) \text { sua } \\
\text { percepção sobre o } \\
\text { desempenho do } \\
\text { aluno foi } \\
\text { alterada? } \\
\end{array}$ & $\begin{array}{l}4-\mathrm{Se} \operatorname{sim}, \mathrm{em} \\
\text { quais aspectos }\end{array}$ & $\begin{array}{c}5 \text { - Qual a sua avaliação } \\
\text { sobre o teste aplicado? } \\
\text { Contribui para a sua } \\
\text { atuação em sala de } \\
\text { aula? }\end{array}$ \\
\hline $\mathbf{P 1}$ & A1 & Não & 6 & Não & - & $\begin{array}{c}\text { Percebi que ela não } \\
\text { tem dificuldades }\end{array}$ \\
\hline $\mathbf{P 2}$ & $\mathrm{A} 2$ & Não & 10 & Não & - & $\begin{array}{c}\text { Não acrescentou } \\
\text { nenhuma informação }\end{array}$ \\
\hline $\mathbf{P 3}$ & $\begin{array}{l}\text { A4 } \\
\text { A5 }\end{array}$ & Não & $\begin{array}{l}\text { Igual aos outros } \\
\text { Ambos iguais aos } \\
\text { outros }\end{array}$ & $\begin{array}{l}\text { Não } \\
\text { Não }\end{array}$ & - & $\begin{array}{c}\text { Não acrescentou } \\
\text { nenhuma informação } \\
\text { Não sei, mas indica } \\
\text { aspectos do } \\
\text { desempenho dos } \\
\text { alunos } \\
\end{array}$ \\
\hline P5 & A6 & Não & 4 & $\begin{array}{l}\text { Não, confirmou o } \\
\text { desempenho }\end{array}$ & - & $\begin{array}{l}\text { Interessante pontuou } \\
\text { algumas dúvidas com } \\
\text { relação a parte } \\
\text { cognitiva e física. } \\
\text { Questões da casa, } \\
\text { alimentação e } \\
\text { transporte para escola } \\
\text { poderiam ser melhor } \\
\text { investigadas } \\
\end{array}$ \\
\hline P6 & A7 & Não & 7 & Não & & $\begin{array}{c}\text { Não acrescentou } \\
\text { nenhuma informação }\end{array}$ \\
\hline P7 & A8 & Já ouvi falar & 9 & Não & . & $\begin{array}{c}\text { Talvez fosse útil para } \\
\text { crianças com mais } \\
\text { dificuldades }\end{array}$ \\
\hline P8 & A9 & Não & 5,5 & $\begin{array}{l}\text { Não (a aluna não } \\
\text { acompanha a 4o. } \\
\text { Série, talvez a } \\
\text { terceira) }\end{array}$ & 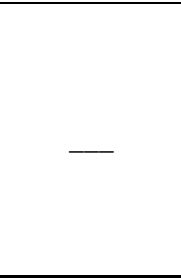 & $\begin{array}{c}\text { Pode ajudar, na hora } \\
\text { de detectar as } \\
\text { dificuldades motoras } \\
\text { específicas, as } \\
\text { necessidades de } \\
\text { auxilio para o } \\
\text { professor } \\
\text { ensinar/ajudar o aluno. }\end{array}$ \\
\hline
\end{tabular}

Quadro 3 - Opinião dos professores sobreaSFA .

Todos os professores, respondendo à terceira questão, referiram quea utilização daSFA não alterou as suas percepções sobreo desempenho do al uno no ambiente de classeregular. Essa negativa resultou na ausência de resposta à quarta questão, uma vez queesta constituía uma extensão daquela, estando condicionada à resposta afirmativa da al teração da percepção.

Contudo, as respostas de quatro professores (P1, P4, P5 eP8) à quinta questão revelaram mudança no quadro perceptivo, uma vez queo foco de atenção del es dirigiu-se ao desempenho do aluno em cenários ampliados de participação 
escolar. A s respostas desses professores à quinta questão do rotei ro deentrevista também demonstraram um impacto daSFA diferente do observado na análise de suas respostas à terceira questão.

Embora a professora P1 tenha negado a mudança na sua percepção, posteriormente, respondendo sobre a contribuição da avaliação para a sua atuação em sala de aula, relatou que com a aplicação daSFA percebeu que sua al una com deficiência auditiva severa não apresentava dificuldades na realização das atividades, atribuindo ao aparel ho auditivo (adaptação) o sucesso na partici pação em todos os ambientes. Esses resultados sugerem que ao avaliar a al una A 1 com a nota 6, em resposta à segunda pergunta do rotei ro de entrevista, a professora P1 pode ter sido influenciada mais pela deficiência e menos pelo desempenho observado. Portanto, no caso deP1, constatou-se queaSFA favoreceu a mudança de uma avaliação com foco na deficiência para uma avaliação direcionada à funcionalidade.

Os professores P5 e P8 apontaram que a avaliação pode auxiliar na detecção de problemas específicos de desempenho nas atividades. Para estes professores, a aplicação daSFA , na suaíntegra, poderia auxiliar numa análisemais pontual do desempenho dos alunos nas diversas atividades escolares, no mapeamento das dificuldades e na orientação do planejamento para atender às necessidades funcionais que interferem no desempenho escolar.

Os professores P2 e P3, cujos alunos (A 2 e A 3), na SFA, obtiveram pontuação total no ambiente de sala de aula, não foram sensíveis ao instrumento, talvez pela ausência de diferença de desempenho destes alunos em relação à classe. Isso se confirma na fala de P7, que, respondendo à quinta questão, conclui que a SFA seria mais útil para aquelas crianças queapresentassem maiores dificuldades. Essa constatação sinaliza que o professor identifica o grau leve da deficiência e queessa condição exerce pouca influência sobre a participação do seu al uno quando comparada à dos demais colegas da classe. O professor P6 não foi sensível ao instrumento, embora seu aluno (A 7) tenha obti do a menor pontuação da amostra.

Diante dos relatos de P1, P2, P3 e P4 (este, respondendo sobre A5), verifica-se que, embora todos os al unos deste estudo tenham sido cadastrados pela Secretaria M unicipal deEducação como al unos com NEE, nem todos apresentavam necessidades diferenciadas dos demais alunos de sua classe. Portanto, a SFA contribuiu para um diagnóstico mais preciso sobre a funcionalidade e a incapacidadedos al unos com deficiência.

Contudo, nem todos os professores foram sensíveis a essa finalidade do instrumento, talvez porque ainda estejam mais preocupados com as características das deficiências e menos atentos à funcionalidade. Diante desses resultados, levanta-se a hipótese de que os professores que tiveram baixa sensibilidade aos propósitos da SFA mantiveram-se orientados pela deficiência. Martins (2006, p.20) ressalta a necessidade deanálise do processo deformação dos professores e demais profissionais não somente na "perspectiva teórico-prática, 
mas também no tocante a atitudes e disposições para com a diversidade dos alunos".

Os resultados deste estudo reforçam a necessi dade de um serviço de apoio que dê suporte aos professores em suas dificuldades junto ao aluno com deficiência, conforme recomendam Oliveira e Leite (2007), Rocha, Castiglioni e Veira (2001) eGlat, (2007).

A Terapia Ocupacional poderia contribuir no ambiente escolar com os conhecimentos específicos da anál ise de desempenho e demandas funcionais de atividades, oferecendo prescrições para minimizar a dificuldade de participação escolar. (DeCARLO, 2006; MOTTA; TAKATORI, 2001; ROCHA; LUIZ; ZULIAN, 2003; JURDI; AMIRALIAN, 2006).

Levar o professor a pensar sobre sua prática conforme preconizam Munguba (2007) éuma estratégia fundamental no sentido demudanças no contexto educacional e, principalmente, no contexto da educação inclusiva. N este presente estudo, acrescenta-se que o uso da SFA com a participação do professor poderia contribuir para o diagnóstico e prescrição de auxílio no desempenho escolar do aluno com NEE .

Embora o presentetrabalho não permita uma análise aprofundada da influência da formação do professor sobresua percepção em relação ao desempenho do aluno, pode-se, entretanto, com base na variabilidade da formação dos participantes, sugerir que, para a efetivação da inclusão em sala de aula, não é suficiente que o professor tenha uma boa formação acadêmica e conhecimentos específicos a respeito das deficiências; énecessário queo professor seja sensibilizado à observação do desempenho do al uno frente às demandas ambientais colocadas pela escola.

\section{CONCLUSÃO}

No presente estudo, não foram identificados problemas importantes de partici pação do aluno com deficiência matriculado em classeregular do primeiro cicl o do Ensino Fundamental. Contudo, esse fato pareceu relacionar-se mais com o grau leve de comprometimento funcional dos alunos emenos com as estratégias adotadas para a sua inclusão escolar.

A SFA mostrou-se adequada para avaliar a participação dos alunos com diferentes acometimentos. A pesar de a aval iação parecer mais apta a avaliar o desempenho de alunos com maior prejuízo da funcionalidade, ela também se revelou importante para apontar os níveis de participação mesmo diante de acometimentos mais leves.

Os resultados obtidos neste estudo sugerem que a aplicação da SFA pode favorecer a percepção do professor com foco na demanda de atividades e propiciar reflexões sobrea funcional idade ea partici pação de seus al unos, tendo- 
se evidenciado os seguintes destaques com rel ação ao impacto da aplicação desse instrumento: necessidade de avaliação da participação fora da sala de aula, entendimento da relação entre o grau de deficiência ea participação, identificação de especificidades do desempenho, importância do recurso adaptado para neutral izar a incapacidadee importância do desvio do foco deatenção da deficiência para a funcionalidade.

\section{REFERÊNCIAS}

AINSCOW, M. O que significa inclusão? Entrevista. Disponível em: <http:/ / www.crmariocovas.sp.gov.br.>A cesso em $13 \mathrm{fev} .2009$.

ANDRÉ, M. E. D. A. Texto, contexto esignificados: al gumas questões na análise de dados qualitativos. Caderno deP esquisa, São Paulo, v.45, p. 66-71, 1983.

ARAÚjO, R. C. T. Significado de recursos adaptados utilizados na educação de deficientes físico. 1998. 90f. Tese (Doutorado em Educação) - FaculdadedeFilosofiae Ciências, Universidade Estadual Paulista, Marília, 1998.

ARAÚJO, R. C. T.; OMOTE, S. A tribuição de gravidade à deficiência física em função da extensão do acometimento e do contexto escolar. Rev. bras. educ. espec. Marília, v.11, n.2, p. 241-254. 2005.

BRASIL, MINISTÉRIO DE EDUCAÇÃO E CULTURA. Secretaria de Educação Especial. Saberes e práticas da inclusão: desenvolvendo competências para o atendimento às necessidades educacionais de aluno com deficiência física/ neuro-motora. $2^{\circ}$ ed. Brasília, 2006.

COSTER, W.; MANCINI, M.; LUDLOW, L. H. Fator structure of the school function assessment. Educational and Psychological M easurement, v.59, n.4, p.665-677, 1999.

DE CARLO, M. M. R. P. Os processos interativos no desenvol vimento humano ea questão da (des)institucionalização das pessoas com deficiência. In MANZINI, E.J. (Org.). Inclusão eacessibilidade. Marília: ABPEE, 2006.

DELMASSO, M. C. S.; ARAUJO, R. C. T. A tribuições de gravidade à deficiência física em função da extensão dos acometimentos e do contexto escolar. In OMOTE, S.; GIROTO, C. R. M.; OLIVEIRA, A. A. S. (Org.) Inclusão escolar: as contribuições da educação especial. Marília, Cultura A cadêmica Editora e Fundepe Editora, 2008.

FERNANDES, E. M.; ANTUNES, K. C. V.; GLAT, R. A cessibilidade ao currículo: prérequisito para o processo ensino-aprendizagem de al unos com necessidades educacionais especiais no ensino regular. In GLAT, R.(org) Educação inclusiva: cultura e cotidiano escolar. Rio de Janeiro; 7Letras, 2007.

GLAT, R.(org) E ducação inclusiva: cultura e cotidiano escolar. Rio de Janeiro; 7Letras, 2007.

GLAT, R., BLANCO, L.M.V. Educação especial no contexto deuma educação inclusiva. In GLAT, R. (Org.). Educação inclusiva: cultura e cotidiano escolar. Rio de Janeiro: 7Letras, 2007.

JURDI, A. P. S.; AMIRALIAN, M. L. T. M.. A inclusão escolar de alunos com deficiência mental: uma proposta deintervenção do terapeuta ocupacional no cotidiano escolar. Estud. psicol. Campinas; v.23, n.2, p. 191-202, 2006. [online]. 
MANCINI, M. C., COSTER, W. J. Functional predictors of school participation by childrem with disabilities. 0 ccupat Therapy Internat, v.11, n.1, p.12-25, 2004.

MANCINI, M. C. et al. Predicting elementary school participation in children with disabilities. A rchives P hysiology R ehability, March v.81, p. 339-347, 2000.

MANZINI,E. J.; CORRÊA, P. M. A valiação da acessibilidadeno ensino fundamental usando atecnologia digital In: REUNIÃ O ANUAL DA ANPED, 2008, Caxambu. A nais: Constituição Brasileira, direitos humanos e educação. Rio de Janeiro: Anped, 2008. v.1. p.1 - 13.

MARTINS, L. A. R. Formação de professores numa perspective inclusive: al gumas constatações. In MANZINI, E. J. (Org.). Inclusão e acessibilidade. M arília: A BPEE, 2006.

MOTTA , M. P.; TAKATORI, M. A assistência em terapia ocupacional sob a perspectiva do desenvolvimento da criança. In: DE CARLO, M.M.R.P.; BARTALOTTI, C.C. Terapia 0 cupacional no Brasil: fundamentos e perspectivas. São Paulo; EditoraPlexus, 2001.

MUNGUBA, M. C. Inclusão escolar. In. CAVALCANTI, A.; GALVÃO, C. Terapia O cupacional : Fundamentação e prática, Rio de Janeiro, Guanabara Koogan, 2007.

OLIVEIRA, A. A. S., LEITE, L. P., Construção de um sistema educacional inclusivo: um desafio político-pedagógico. Ensaio: aval. Polít. Públic. Educ, São Paulo; v.15, n.7, p. 511$524,2007$.

OMOTE, S. Inclusão: da intenção à realidade. In: . Inclusão: da intenção à realidade. Marília: Fundepe, 2004.

OMS. Organização Mundial da Saúde. CIF: Classificação Internacional de Funcionalidade, Incapacidadee Saúde. São Paulo, EDUSP, 2003.

ROCHA, E. F; CASTIGLIONI, M. C.; VIEIRA, R. C. A inclusão da criança com deficiência na escola comum: reflexões sobre o papel da terapia ocupacional. R evista Terapia 0 cu pacional da U niversidade de São Paulo. São Paulo: v.12, n.1/ 3, p.8-14, 2001.

ROCHA, E. F.; LUIZ, A.; ZULIAN, M. A. R. Reflexões sobre as possíveis contribuições da terapia ocupacional nos processos de inclusão escolar. R ev. Ter. O cup. U niv. São Paulo, v. 4, n. 2, p.72-8, 2003.

SCHENKER, R., COSTER, W.J., PARUSH, S. Neuroimpairments, activity perfomence, and participation in children with cerebral palsy mainstreamend in elementary schools. D evel op M ed Child N eurology, v.47, p. 808-814, 2005

VERBRUGGE, L. M.; JETTE, A. M. Thedisablement process. Soc. Science. M ed, v.38, p.1-14, 1994.

Recebido em: 01/ 03/ 2010

Reformulado em: 14/ 07/ 2010

A provado: 19/ 07/ 2010 